\title{
A KNOWLEDGE-BASED SYSTEM FOR ASSISTED VENTILATION OF PATIENTS IN INTENSIVE CARE UNITS.
}

Michel DOJAT, Laurent BROCHARD ${ }^{*}$, F. LEMAIRE $^{*}$ and Alain HARF ${ }^{* *}$

Institut National de la Santé et de la Recherche Médicale INSERM U 296,

** Département de Physiologie, and ${ }^{*}$ Service de Réanimation Médicale, Hôpital Henri Mondor, Créteil, France.

Address for correspondence : M.DOJAT

INSERM U296

Faculté de Médecine

8, rue du Général SARRAIL

94010 CRETEIL, FRANCE

Phone: 33148984603

Fax: 33148981777

e-mail: dojat@laforia.ibp.fr 


\begin{abstract}
The procedure for weaning a patient with respiratory insufficiency from mechanical ventilation may be complex and requires expertise obtained by long clinical practice. We designed a knowledge-based system for the management of patients receiving respiratory support and implemented a weaning procedure. The system is intended for patients whose spontaneous respiratory activity is assisted by a Hamilton Veolar ventilator delivering a positive pressure plateau during inspiration (Pressure Support Ventilation mode). Our closed-loop real-time system running on a Personal Computer continuously adapts the assistance provided by the ventilator to the patient's evolution, and indicates when the patient can be withdrawn from the ventilator. Three parameters are used to appreciate the "respiratory comfort" of the patient: breathing frequency, which we consider the most informative index, tidal volume and end-tidal $\mathrm{CO}_{2}$ pressure. A preliminary study of 19 patients was performed to evaluate the ability of our system to adapt the assistance to the patient's needs, with the main objective of facilitating weaning by gradually lowering the level of assistance. In 10 of these patients, considered as good candidates for weaning on the strength of objective criteria, the system maintained the breathing pattern in a zone of comfort for $95 \%$ of the period of assisted ventilation and stated that they were "weanable". This was consistent with the clinical evolution of all 10 patients. These results show that such a system can provide effective management for mechanically ventilated patients.
\end{abstract}

Keywords:

Assisted ventilation, Knowledge-based system, Medical decision-making, Process control, Real-time, Weaning from mechanical ventilation. 


\section{INTRODUCTION}

In Intensive Care Units (ICUs), the management of a patient receiving respiratory support may be complex, and requires considerable clinical expertise. A common strategy is to place the patient as soon as possible under partial mechanical assistance such as Pressure Support Ventilation (PSV), so that he can gradually participate in the work of breathing. The clinician adjusts the ventilator settings according to the physiological needs of the patient, and adapts the level of assistance so as to maintain the patient in a state of "comfort". The procedure of weaning from the ventilator may be a difficult step for some patients who have been ventilated for long periods, especially those ventilated for acute exacerbation of chronic obstructive lung disease. Before the clinican proceeds to withdraw the ventilator, he should appreciate the patient's capacity to breathe without assistance. Recently, several advances have been made in working out strategies for difficult-to-wean patients [1, $2,3]$. At best, these strategies need a constant monitoring of the ventilated patient, in order to adjust the ventilator settings to the evolution of the patient's respiratory status. For this reason, they may be hard to use in clinical practice. The object of this

study was to build a computer-controlled system to implement such a strategy. Because most of the control of mechanical assistance and of weaning decisions is based on objective data, the clinician's reasoning is essentially data driven. Thus, a rule-based approach is a priori well adapted to the representation of the expert knowledge.

In the field of mechanical ventilation, many systems using Artificial Intelligence techniques have been proposed such as VM [4], VQ-ATTENDING [5], ESTER [6], KUSIVAR [7] and COMPASS [8]. Each system has its own characteristics. For example, KUSIVAR and VM manage different ventilatory modes, COMPASS is designed for patients with severe respiratory failure (Acute Respiratory Distress Syndrome), and ESTER needs the participation of the clinical staff to feed the system with physiological indices. These systems supply advice to the clinician but do not 
act directly on the ventilator to adjust its settings ; this is because of the complexity of the problems they are trying to solve, and the extreme diversity of the patients they ventilate.

GANESH, the system described in this paper, deals with a limited problem and has two main features: i) it is designed to work for a specific period of mechanical ventilatory support, while the patient is recovering a spontaneous breathing activity, at a time when a strategy is required to wean the patient from the ventilator, and ii) only one mode of assisted ventilation is controlled by the system: Pressure Support Ventilation (PSV).

With these specifications in mind, we constructed GANESH, which is a closed-loop system. GANESH acquires and processes a set of data, appreciates the current respiratory status and its evolution, establishes a diagnosis of respiratory status severity, determines the action to be taken, and implements it by acting directly on the ventilator. In addition, as a part of its diagnostic capacity, it indicates when the patient can be weaned from the ventilator.

In this paper, we describe the prototype of GANESH, and report the clinical tests performed on 19 patients. These tests were designed to evaluate the ability of our system to adapt the respiratory assistance to the patient's needs, in order to facilitate weaning by gradually lowering the level of assistance. 


\section{MATERIALS AND METHODS}

\section{Description of the expert system GANESH}

\section{Architecture}

We used three fundamental parameters to assess the patient's respiratory status: respiratory rate $(\mathrm{RR})$, tidal volume $(\mathrm{Vt})$, and end-tidal partial pressure of carbon dioxide $\left(\mathrm{PetCO}_{2}\right)$.

As shown in Figure 1, the system uses conventional serial communication protocols (RS 232) to acquire patient's data from the ventilator (RR, Vt) and from a gas analyzer $\left(\mathrm{PetCO}_{2}\right)$. These parameters are acquired and averaged at a sampling frequency of $0.1 \mathrm{~Hz}$ over periods of 2 to 10 minutes.

During Pressure Support Ventilation (PSV), i.e. the mode of assisted ventilation chosen, a preset level of pressure is delivered as a plateau during each spontaneous inspiration. For a high level of pressure, the work of breathing performed by the patient is minimal, and the respiratory muscles are hardly loaded. By contrast, when the level of pressure is low, most of the work of breathing is performed by the patient. When insufficient pressure is delivered to the patient, respiratory discomfort occurs and a pattern of rapid shallow breathing is observed. During PSV, the patient controls his own respiratory rate, inspiratory time and tidal volume. A positive correlation between tidal volume and the level of pressure support, and an inverse correlation between the respiratory rate and the level of pressure support have been observed [1,2]. The principle of the system described here is to adapt the pressure support level so that the respiratory rate of the patient is maintained within a range of 12 to 28 breaths per minute, the tidal volume is above the minimum threshold and $\mathrm{PetC}_{2}$ below the maximum threshold. Lastly, the system tries automatically to reduce the pressure support level, to facilitate gradual weaning from the ventilator.

From the level of pressure support which the patient needs to remain in the zone of comfort described above, GANESH evaluates the degree of abnormality of 
the respiratory system. When a low level of assistance is sufficient to maintain the breathing pattern in the zone of comfort $\left(9 \mathrm{cmH}_{2} \mathrm{O}\right.$ for a tracheally intubated patient), the possibility of permanent weaning from the ventilator is envisaged [9]. When this level of assistance is maintained for a specified period of time, the patient is diagnosed by the system as fit to be weaned.

After each data acquisition, the control-loop real-time system consults the knowledge base, establishes a diagnosis and acts on the ventilator. It works without any intervention from the clinical staff except at the initialization of the system. A cycle can be stopped by specific action of the physician on the keyboard. For each expertise, a simple report is displayed on the computer screen, printed and saved. The report includes the ventilatory status of the patient, the actions performed, and the ventilator settings used.

We devised a way in which the system was able to run on a microcomputer placed at the of the patient's bedside. The prototype was connected via two serial ports to a Veolar ventilator (Hamilton, Bonaduz AG, Switzerland) especially adapted for this purpose by the manufacturer. A gas analyser (5200 Ohmeda, Maurepas, France) was connected to another serial port. The application was written in $\mathrm{C}$ language. An inference engine (written in C) order $0^{+}$(GSI, Paris, France) was used. The knowledge base contained 142 rules.

In this system all ventilator alarms remain available throughout the period of automatic control. If no information is sent by the computer to the ventilator for a period of one minute, the ventilator automatically switches to the set-up imposed by the settings placed on its front panel. 


\section{Knowledge representation}

\section{- Knowledge organization}

The reasoning implemented in our system is based on the expertise in the management of weaning acquired by the clinical staff of the medical ICU of the Henri Mondor Hospital, and on published data concerning PSV [1, 2, 3]. We represented the expertise with production rules in zero order logic. The complete organization of the reasoning is shown in Figure 2.

We divided the knowledge base into several blocks encoding different types of knowledge representative of different cognitive steps. Details concerning these blocks are given below, together with some typical examples.

The first block infers information from the data provided by the clinician about the patient, including anthropometric data, presence of chronic lung disease, and mode of assistance. This information is representative of Static Knowledge.

Example:

rule 3: IF the patient is tracheostomized

THEN pressure support before weaning can be envisaged $=5 \mathrm{cmH}_{2} 0$

The second block assesses the severity of the ventilatory dysfunction from the level of pressure support needed by the patient, and determines the duration of the observation period before pressure support can be decrease.

Example:

rule 2: IF pressure support $\geq 15$ AND pressure support $<20 \mathrm{cmH}_{2} 0$ THEN the period of observation $=240 \mathrm{~min}$

The third block assesses the respiratory status of the patient and compares it to the predetermined range of comfort. It therefore evaluates the quality of the ventilation. 
Example:

rule 3: IF $\mathrm{Vt}<$ minimum Volume OR $\mathrm{PetCO}_{2}>55 \mathrm{mmHg}$ THEN ventilation $=$ "insufficient"

The fourth block appreciates evolution of the respiratory status with time.

Example:

rule 4: IF ventilation =("tachypnea" OR "insufficient")

AND the previous ventilatory checkUp = "normal"

THEN stability = "bad"

The fifth block defines, in relation to the previous modules, the action to be performed on the ventilator settings and the time that must elapse before a new expertise is launched (during this period, fresh data are acquired) .

Example:

rule 5: IF stability = "bad"

THEN pressure support $=$ previous pressure support $+4 \mathrm{cmH}_{2} \mathrm{O}$

AND new expertise $=5 \mathrm{~min}$

The sixth block concerns the last step of the weaning procedure: when only a low level of assistance is needed, the respiratory status of the patient is observed for a predetermined period of time, to appreciate his ability to be weaned from the ventilator. If the patient tolerates this low level of pressure support throughout the observation period, the system will indicate that he can be weaned from the ventilator. 
Example:

rule 6: IF the stability period < observation period before weaning

THEN weaning = "in observation"

AND stability period $=$ previous stability period + duration of the expertise

AND new expertise $=2 \min$

All blocks except the first encode dynamic knowledge which is updated after each data acquisition.

A specific block of rules deals with the alarms of the ventilator (apnea, disconnection, or hypoventilation).

Example:

rule 7: IF ventilation $=$ "hypoventilation"

THEN raises Alarm 4

AND switch to Mechanical Ventilation

\section{- Temporal aspects}

The temporal dimension has been developed in this system, and three aspects are represented:

- evolution of the patient's respiratory status: the history of respiratory status is assessed by a symbolic entity which summarizes three previous consultations. Therefore, decisions are influenced both by the present status and by the patient's evolution.

- reference to specific periods: several local clocks store the duration of specific periods (such as periods of stable respiratory status). The patient's current status is analyzed with reference to these periods.

- asynchronous events: when an alarm occurs on the ventilator (patient's disconnection, or apnea), a special reasoning is processed : acquisition is stopped to avoid 
accumulating invalid data during disconnection. In case of apnea, the pressure support level can be either decreased in case of hyperventilation or switched to controlled mechanical ventilation in case of hypoventilation.

\section{- Interface}

The user interface is designed to be concise and free of information overload. The implementation and professional use of decision support systems in the medical field is surprisingly slow and some of the reasons may be found in the lack of attention given to the designing of the user interface [10]. In different windows, we summarize the patient's parameters, ventilator settings, tolerance of parameters variations, the GANESH consultation report, and alarms [Figure 3].

\section{- Protocol and patients}

After approval by the Ethical Committee of our University, we performed a preliminary study of 19 patients, to verify that the system was able to keep the patients comfortable and reduce the assistance adequately during recovery. More precisely, the study was designed to explore two objectives: 1) whether the system was able to keep the patient's breathing pattern inside the predetermined zone of comfort and 2) whether a gradual decrease in ventilatory support would be observed in patients considered as good candidates for weaning.

Patients were selected for the study when the physicians in charge had decided to start trying to wean them from the ventilator because of sufficient improvement in their respiratory status. All patients were tracheally intubated, to allow mechanical ventilation. None of them was still experiencing difficult oxygenation that could be considered to impede weaning or necessitate high levels of $\mathrm{FiO}_{2}(\geq 0.5)$. When the study began, the patients had been ventilated for several days in the PSV mode of assisted ventilation, and hemodynamic stability over the previous 24 hours was required. The system did not involve additional work for the 
clinical staff and did not interfere with the usual management of the patients: for instance they had endotracheal suctioning as often as required during the study.

Patients were divided in two groups, according to the values of their preweaning indices. Positive criteria for these indices were the following: oxygen saturation of the arterial blood $\left(\mathrm{SaO}_{2}\right)>90 \%$ with an inspired oxygen fraction of 0.4 or less, negative maximal inspiratory force greater than $25 \mathrm{cmH}_{2} 0$, respiratory rate below 35 breaths per minute after one minute of disconnection from the ventilator, and vital capacity greater than $10 \mathrm{ml} / \mathrm{kg}$. When at least three of these criteria were met patients were considered as good candidates for weaning: 10 patients fulfilled this condition (group 1). The second group (group 2) was made up of patients who failed to meet the preweaning criteria $(n=9)$. Table 1 gives the characteristics of the patient population. The two groups of patients were comparable for age, Simplified Acute Physiology Score (SAPS) [11] and weight.

At the beginning of the study, the system provided all the patients with $15 \mathrm{cmH}_{2} \mathrm{O}$ of pressure support. The system was then left in complete control of ventilation for a period that varied from 8 to 24 hours. The duration of this period was determined, either by the decisions of the system (proposition to withdraw mechanical ventilation or proposition to switch to controlled mechanical ventilation) or by the therapeutical constraints affecting each individual patient. To consider the patient in a zone of "respiratory comfort" the following three conditions had to be satisfied: respiratory rate between 12 and 28 breaths/min, tidal volume above $250 \mathrm{ml}$ for patients weighting less than $55 \mathrm{~kg}$, and above $300 \mathrm{ml}$ for those weighting more than $55 \mathrm{~kg}$, and $\mathrm{PetCO}_{2}$ below $55 \mathrm{mmHg}$ (or below $65 \mathrm{mmHg}$ for patients with chronic obstructive lung disease). In the zone of respiratory comfort, GANESH maintained or tried to lower the assistance level. At the end of the period of ventilation with GANESH, the final diagnosis made by the system was noted with regard to the possibility of withdrawing mechanical ventilation . 


\section{RESULTS}

As expected, the average duration of ventilation with GANESH was longer for group 2 patients, who were not considered weanable, than for group 1 patients who fulfilled the preweaning criteria (Table 2). The mechanical assistance provided by the system was adequate since it kept the patients in the zone of respiratory comfort most of the time (95\% of the total ventilation period for group 1 patients and $72 \%$ for group 2 patients). The average values for the three physiological parameters $\mathrm{RR}, \mathrm{Vt}$ and $\mathrm{PetCO}_{2}$ were similar for the two groups, inside and outside the zone of respiratory comfort (Table 3). The average pressure support level was $11 \mathrm{cmH}_{2} \mathrm{O}$ for group 1 and $21 \mathrm{cmH}_{2} \mathrm{O}$ for group 2.

When the patient was outside the zone of respiratory comfort, we defined an intermediate zone, in which the patient had an RR of 28 to 35 breaths/min (intermediate frequency) and three critical zones: a low respiratory frequency (bradypnea) when RR was $\leq 12$ breaths/min, a high respiratory frequency (tachypnea) when RR > 35 breaths/min and a low tidal volume when $\mathrm{Vt}$ was $<250$ (or 300) $\mathrm{ml}$. Figures 4 and 5 indicate the period of ventilation spent outside the zone of respiratory comfort, expressed in percent of the duration of total ventilation with the system, for group 1 patients (Figure 4) and group 2 patients (Figure 5) with an average of $5 \%$ for group 1 and $28 \%$ for group 2 . For each patient, the contribution of intermediate frequency, bradypnea, tachypnea or low $\mathrm{Vt}$ to the inadequate ventilation is shown. For the two groups, intermediate frequency was the predominant cause of inadequate ventilation (79\% for group 1 and 63\% for group 2). The critical cases of bradypnea, low Vt, and tachypnea, respectively constituted 12, 7 and $4 \%$ of the inadequate ventilation for group 1 patients, and 17,7 and $13 \%$ for group 2 patients. More group 2 than group 1 patients exhibited tachypnea. 
With the GANESH system, group 1 patients were kept out of the critical zones for $99 \%$ of the duration of total ventilation, and group 2 patients, for $90 \%$ of this duration.

At the end of the period of assisted ventilation with the system, all the patients in group 1 were stated to be weanable by GANESH: accordingly, they were withdrawn from the ventilator and the weaning was considered successful, since they were able to breathe alone without any sign of respiratory discomfort. For group 2 patients, however, mechanical assistance was continued, as advised by GANESH. 


\section{DISCUSSION}

The system described in this study was designed to optimize the monitoring and the weaning procedure for mechanically ventilated patients.

\section{- Medical aspects}

Our aim with this system was to validate a type of reasoning linked to Pressure Support Ventilation (PSV) in order i) to ventilate patients according to their physiological needs and ii) to withdraw mechanical assistance progressively, with the final objective of weaning the patient from the ventilator altogether. This constitutes an approach to the automatization of the weaning procedure.

During weaning from mechanical ventilation, the respiratory muscles of the patients, who are often weakened by denutrition, sepsis, disuse atrophy or electrolyte disorders, have to bear high workloads, due to lung infection, high airway resistance and the presence of the endotracheal tube and ventilator circuit. Therefore, in most instances, failure of weaning from mechanical ventilation does not result from impaired gas exchange and hypoxemia, but from the inability of the respiratory muscles to cope with the imposed workload [12]. This generally leads to the fast shallow breathing which precedes hypercapnia, respiratory acidosis and respiratory arrest. That is why modes of ventilation designed to support respiratory muscle work have been developed and used as means of gradually separating the patient from the ventilator $[1,2,3]$. The system described here adjusts the level of pressure support by assessing its effects on the breathing pattern of the patient. In the PSV mode, the patient triggers the assistance by his inspiratory effort and switch it off on expiration. Several recent studies $[1,2,3]$ have shown the advantages of this mode especially in reducing the subject's respiratory work while allowing satisfactory gas exchange. It seems an increasingly promising mode of ventilation, as it provides the respiratory muscles with physiological assistance. Brochard et al [1,9] have shown 
the advantage of this mode for weaning the patient compared to conventional methods.

PSV is not a volume-controlled mode. Thus, any alteration in respiratory mechanics alters the volume delivered at inspiration. This is why it may be necessary to change the level of PSV frequently. The problem for the clinician is to evaluate the patient's needs correcty, with the relevant indices. As indicated in a previous study [12], the respiratory rate is in many circumstances a precise reflection of how well the respiratory muscles are adapted to the imposed workload. When the muscles deal with an excessive load, tachypnea rapidly ensues. In our study, respiratory rate was the parameter most often used to change the pressure support level. Our results also show that Vt was a good index for assessing the adaquacy of assistance, but that $\mathrm{PetCO}_{2}$, as used in the present study, was not very useful in this respect. After comparable durations of ventilation for the two groups (10 hours and 14 hours for groups 1 and 2 respectively), the level of assistance provided by the system in order to maintain physiological parameters in an acceptable range was $10 \mathrm{cmH}_{2} 0$ higher for group 2 (non weanable patients) than for group 1. Like other authors [12, 13], we postulated that the use of simple non-invasive indices to characterize the patient's respiratory status is pertinent to the management of the weaning process. The present clinical results support this approach.

Clearly, our study shows that rational checking of the level of assistance and the breathing pattern allows computer control of mechanical assistance and enables a decision to be proposed about weaning.

\section{- Clinical decision support system}

Several modalities of servo-controlled PSV have been proposed, such as those of Hamilton and Taema with Veolar and Cesar ventilators respectively [14], both of them based on conventional algorithms. Basically, these modalities monitor a physiological parameter like tidal volume or spontaneous frequency and use it as a variable for the servo-control of PSV. The adjustment of PSV maintains either minute 
volume or spontaneous frequency at a specific target level fixed by the clinician. Different negative aspects of these modes of control have been reported [14]. Moreover, the algorithms on which they are based, do not reflect the attitude of the physician who is trying to maintain the patient in a overall respiratory comfort in relation to a set of parameters and to their evolution. By using a rule-based approach, we were able to model the clinician's expertise and adapt the decision to different clinical situations. The rule-based formalism is efficient for the expertise considered because the modelized knowledge consists of specific rules applied to explicit entities in the relevant domain. The structure of the knowledge base in blocks, which represent several clusters of knowledge [15], facilites the modelization of the control of the reasoning (the firing of rules) and preserves the steps in this reasoning. Specific rules (metarules) activate the blocks, depending on the context.

The usual problem of the response time of a such rule-based system in real time applications is not crucial in the present application. The ventilation is essentially a low frequency phenomenon $(<0.02 \mathrm{~Hz})$ and the actions in alarm cases (apnea or disconnection) were performed in less than 2 second, with a 286 processor at $12 \mathrm{MHz}$. The patients were never in critical regions (low Vt, bradypnea, tachypnea) for longer than the time required to identify a situation as such (period of data acquisition of 2 or $5 \mathrm{~min}$ ). In ICU, the quantity of data available on any one patient is enormous. It is important to determine what data is pertinent and how often is necessary to sample and store it. We chose to use three relevant physiological indices, collect them every 10 seconds and store them every 2, 5, or 10 minutes. The clinical results justify our choice.

In our study, the system managed the ventilation of 19 patients correctly, and diagnosed their ability to be weaned. Although, this approach will have to be validated for a larger sample of patients, including more with prolonged difficulties of separation from the ventilator, these preliminary results indicate that the decisons taken by the system seem reliable. 
Information technology must be used to improve the quality of medical care. In our opinion, systems capable of monitoring physiological data in real time and applying therapeutical actions in a well-known environment, would prove very helpful to physicians. Clearly, the necessary formalization of the expertise for its implementation on a computer implies the rationalization of clinical methods, and may allow future standardization. It has been demonstrated that medical decision making by physicians can be improved by incorporating certain formal decision-aids into clinical routine [16].

Future developments will require enlargement of the knowledge base to include other physiological parameters than those currently used, in order to estimate more precisely the respiratory comfort of the patient, and to assess his physiological needs with a view to optimizing the mechanical assistance. On the basis of the working prototype described here, we are exploring a general architecture for knowledge-based systems which would support different clinical procedures in anesthesia and intensive care.

\section{Acknowledgments}

The authors wish to thank Dr. Josef Brünner from the Hamilton Company for his assistance in helping to implement the communication between the computer and the ventilator, and for his useful comments, and Martine Laforest and Dominique Touchard for their active participation in the clinical evaluation of our prototype.

This study was supported by a grant from la Délégation à la Recherche Clinique de l'Assistance Publique - Hôpitaux de Paris. 


\section{REFERENCES}

1. BROCHARD L, PLUSKWA F, LEMAIRE F. Improved efficacy of spontaneous breathing with inspiratory pressure support. Am Rev Respir Dis 1987;32:1011-16.

2. BROCHARD L, HARF A, LORINO H, LEMAIRE F. Inspiratory pressure support prevents diaphragmatic fatigue during weaning from mechanical ventilation. Am Rev Respir Dis 1989;139:513-21.

3. MacINTYRE NR. Respiratory function during pressure support ventilation. Chest 1986;89:677-83 .

4. FAGAN LM. Representing time dependant relations in a medical setting [dissertation]. Palo Alto (CA): Univ of Stanford, 1980.

5. MILLER PL. Goal directed critiquing by computer: ventilator management, Comput Biomed Res 1985;18:422-438.

6. HERNANDEZ-SANDE C, MORET-BONILLO V, ALONSO-BETANZOS A. ESTER: an expert system for management of respiratory weaning therapy. IEEE Trans Biom Eng 1989;36:551-564.

7. RUDOWSKI R, FROSTELL C and GILL H. A knowledge-based support system for mechanical ventilation of the lungs. The KUSIVAR concept and prototype. Comput Biomed Res 1989;30:59-70.

8. SITTIG DF. A computerized patient advice system to direct ventilatory care [dissertation]. Salt Lake city (UT): Univ of Utha, 1986.

9. BROCHARD L, RUA F, LORINO H, LEMAIRE F, HARF A. Inspiratory pressure support compensates for the additional work of breathing caused by the endotracheal tube. Anesthesiology 1991;75:739-745.

10. ZIMOLONG B, SHIMON YN. RAY EE, and SALVENDY G. On the limits of expert systems and engineering models in process control. Behavior and information technology 1986;6:5-36. 
11. LE GALL JR, LOIRAT P, ALPEROVITCH A, GLASER P, GRANTHILL C, MATHIEU D, MERCIER P, THOMAS R, VILLIERS D. A simplified acute physiological score for ICU patients. Crit Car Med 1984;12:975-977.

12. TOBIN MJ, PEREZ W, GUENTHER SH, SEMMES BJ, MADOR MJ, ALLEN S, LOTADO RF, DANTZKER DR. The pattern of breathing during successful and unsuccessful trials of weaning from mechanical ventilation. Am Rev Respir Dis 1986;134:1111-18.

13. MILIC-EMILI J. Is weaning an art or a science ? Am Rev Respir Dis 1986;134: 1107-1108.

14. BOYER F, BRUNEAU B, GAUSSORGUES P, JAY-LASSONNNERYS, ROBERT D. Aide inspiratoire avec asservissement du niveau de pression : volume ventilé versus fréquence ventilatoire. Réan Soins Intens Med Urg 1989;5:227-32.

15. GOMEZ F, CHANDRASEKARAN B. Knowledge organisation and distribution for medical diagnosis. IEEE Transactions on systems, man, and cybernetics 1981; 11:34-42.

16 OHMANN C. Methods, statistical performance and clinical benefit of decision support systems. RBM 1991;13:81-83. 


\section{FIGUREs}

Figure 1:

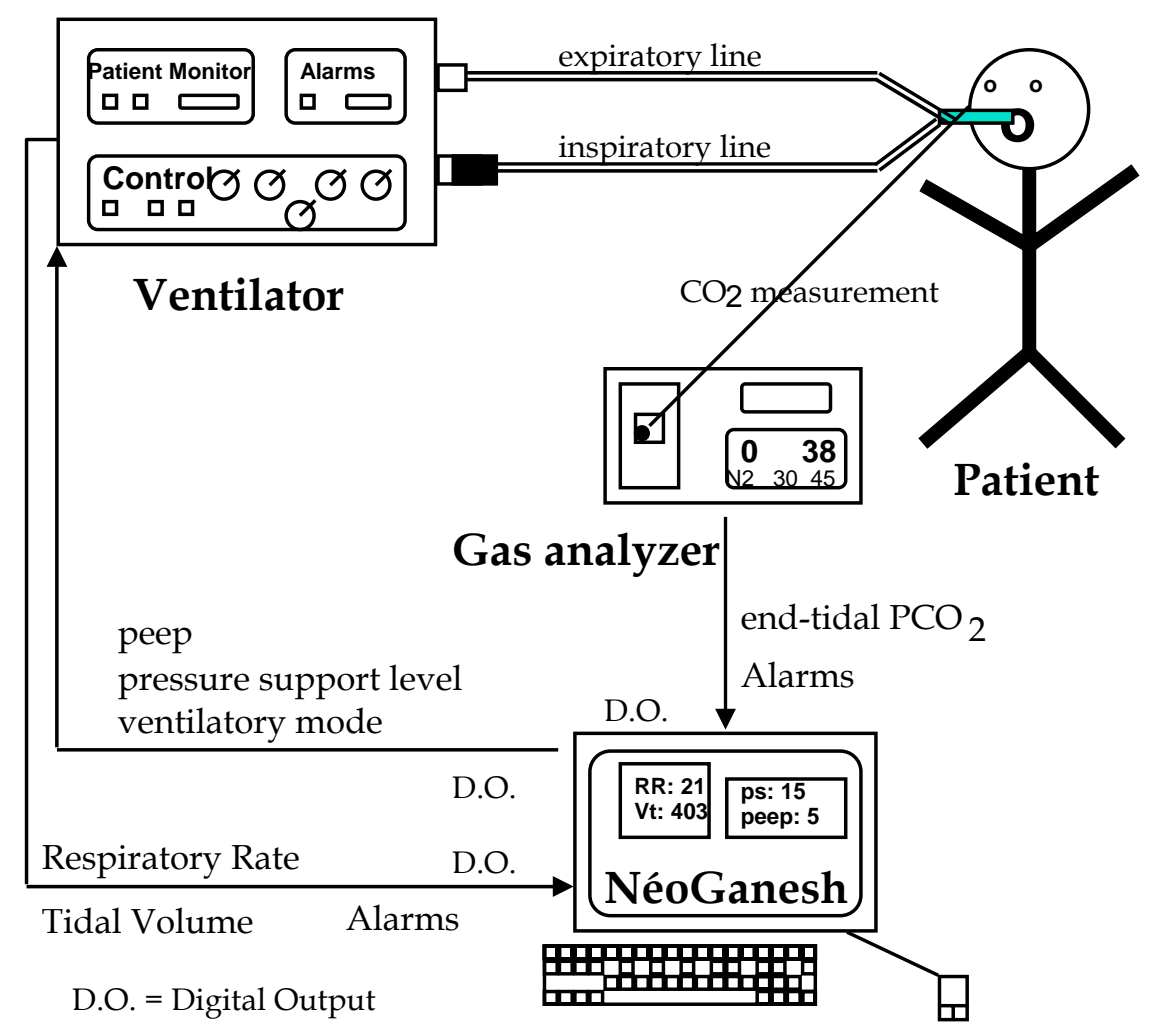

Information exchange in the GANESH system.

The communications with the ventilator and gas analyser use the RS 232 protocol. GANESH is implemented on a PC computer. 
Figure 2:

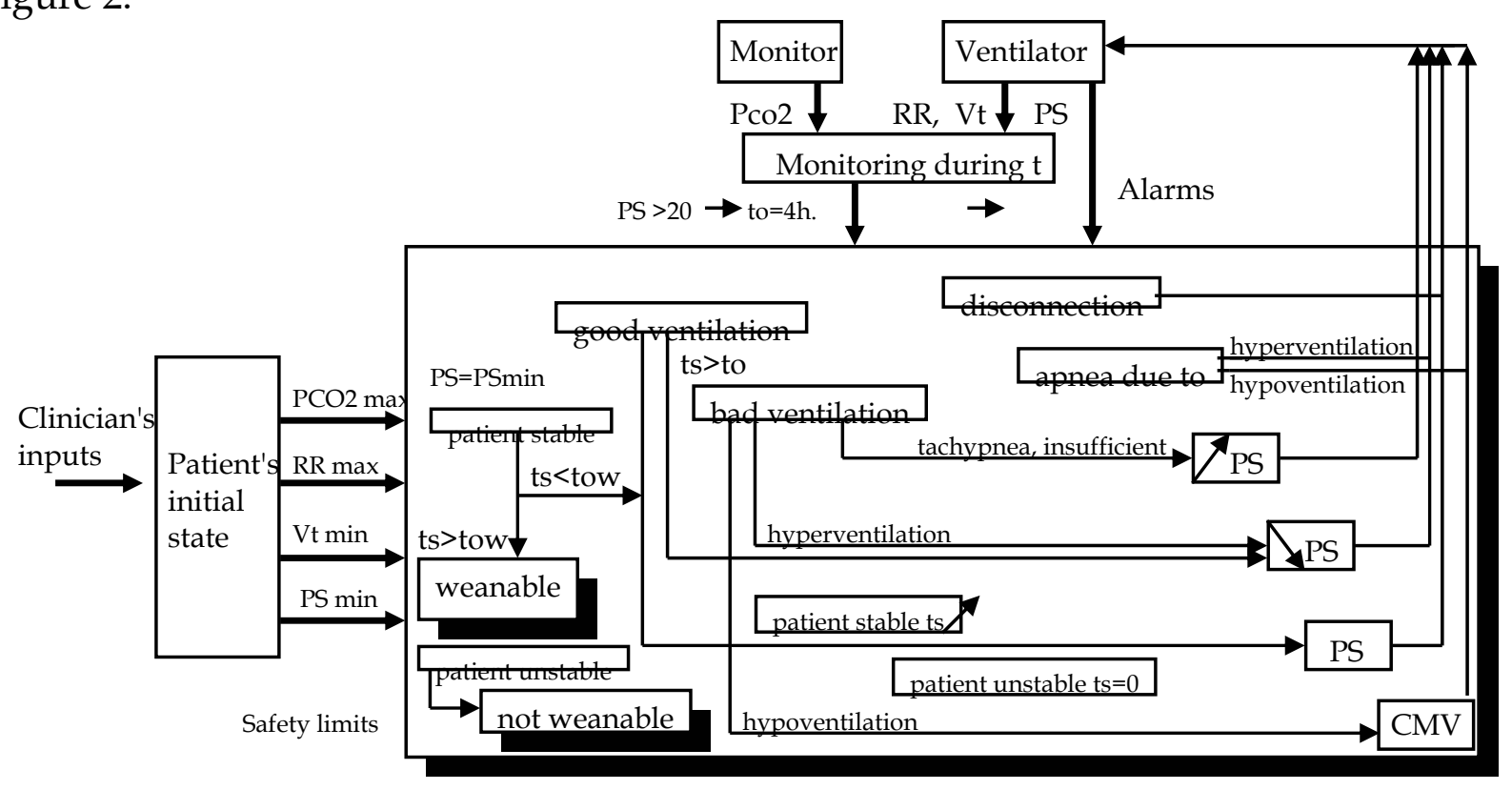

Organization of the knowledge base.

Abbreviations : ts: period of stability, to: duration of patient's observation period, tow: duration of observation before weaning, CMV: Controlled Mechanical Ventilation, PS : level of pressure support.

This diagram shows the different situations in which the ventilator settings can be modified. At the initialization, the values entered by the clinician are used by the system to fix safety limits. When respiratory status is "good", i.e., the patient is in the zone of respiratory comfort (see definition in the legend to Table 2) assistance is reduced for a predetermined period of time (to). When PS reaches a threshold (PSmin), a special observation period is initiated to appreciate whether or not the patient can be weaned. The system manages two alarming situations: disconnection and apnea. Apnea requires specific reasoning, depending on the duration of the alarm. 
Figure 3:

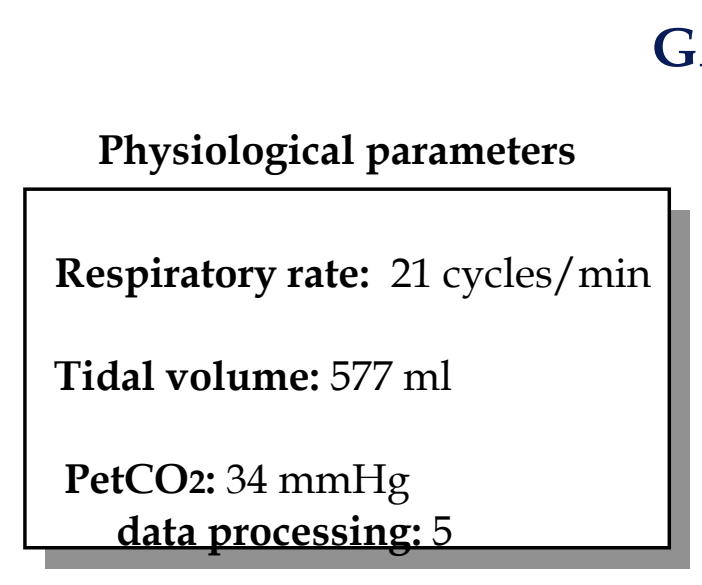

Patient's check-up

\section{Deductions:}

No change in the ventilator settings after patient disconnection.

New expertise in $2 \mathrm{mn}$.

Data acquisition. Please wait starting: Mar 25 09:16:09 1992

\begin{tabular}{|ll|}
\multicolumn{1}{l}{ Ventilator } \\
Mode & $:$ Pressure Support \\
Peep & $: 4.7 \mathrm{cmH} 2 \mathrm{O}$ \\
Trigger & $:-2.0 \mathrm{cmH} 2 \mathrm{O}$ \\
Fio2 & $: 32 \%$ \\
Level of PS & $: 15 \mathrm{cmH} 2 \mathrm{O}$ \\
\hline
\end{tabular}

Alarms

Disconnection.

Time elapsing before reconnection: $3 \mathrm{~min}$.

Thresholds

Vt: 300 Vt apnea: 975

PetCO 255 PS: 9

RR: 28

User's interface.

Differents units summarize the main information. Top left: patient's current data and the number of data acquisitions performed (data processing). Top right: the ventilator settings. The bottom left unit indicates the patient's status and the action performed. In the clinical case represented, the patient was disconnected from the ventilator for suctioning, and after reconnection, the system did not modify the level of pressure support. A new data acquisition was then performed for 2 minutes (new expertise in $2 \mathrm{~min}$ ). The alarm unit indicates the important alarms occurring during data acquisition (here, reconnection of the patient after 3 minutes of disconnection). The bottom right unit represents the physiological thresholds used to measure minimum tidal volume $(\mathrm{Vt})$, maximum $\mathrm{PCO}_{2}(\mathrm{Pco} 2)$, maximun respiratory rate $(\mathrm{RR})$, 
maximum tidal volume after a apnea (VtApnea), and the minimum level of pressure support necessary before weaning can be envisaged (PS). 
Figure 4:

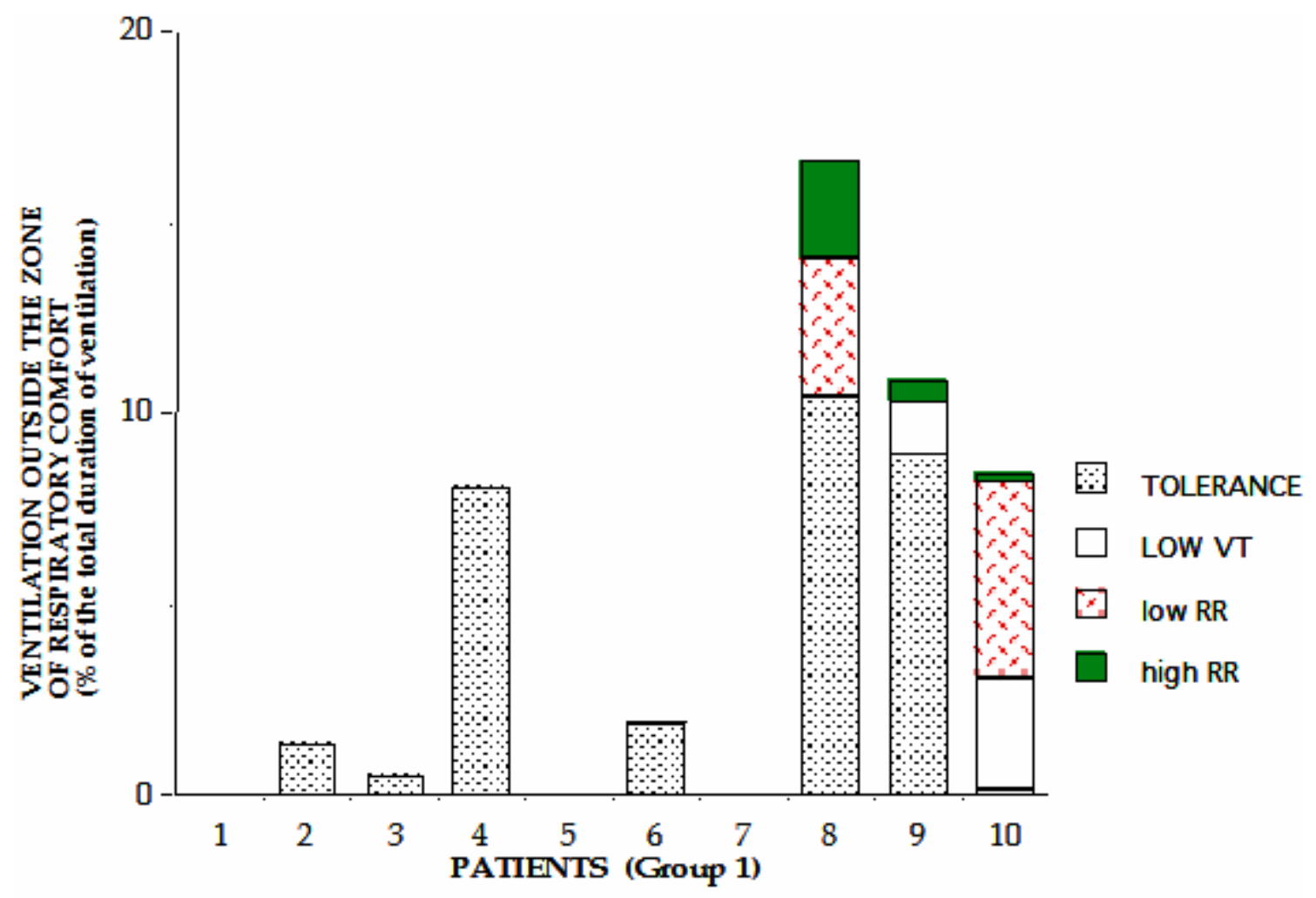

Duration of ventilation outside of the zone of respiratory comfort for each patient with positive criteria for preweaning tests (group 1).

The mean period spent outside the respiratory comfort zone represents $5 \%$ of the total duration of ventilation. The figure also shows the contributions to inadequate ventilation of intermediate frequency (28 breaths $/ \mathrm{min}<\mathrm{RR}<35$ breaths $/ \mathrm{min}$ ), bradypnea ( $\mathrm{RR}<12$ breaths/min), tachypnea ( $\mathrm{RR} \geq 35$ breaths/min) and low $\mathrm{Vt}$ ( $<250 \mathrm{ml}$ and $<300 \mathrm{ml}$ for weights of $<55 \mathrm{Kg}$ and $\geq 55 \mathrm{Kg}$ respectively).

Patients \#1, \#5 and \#7 were always in the zone of respiratory comfort. In group 1, the longest time spent outside comfortable limits was seen in patient \#8 (17\% of the total time of the study, but most of it was spent in the intermediate zone).

The mean periods spent in bradypnea, tachypnea or low Vt represent $1 \%$ of the total duration of the ventilation. 
Figure 5:

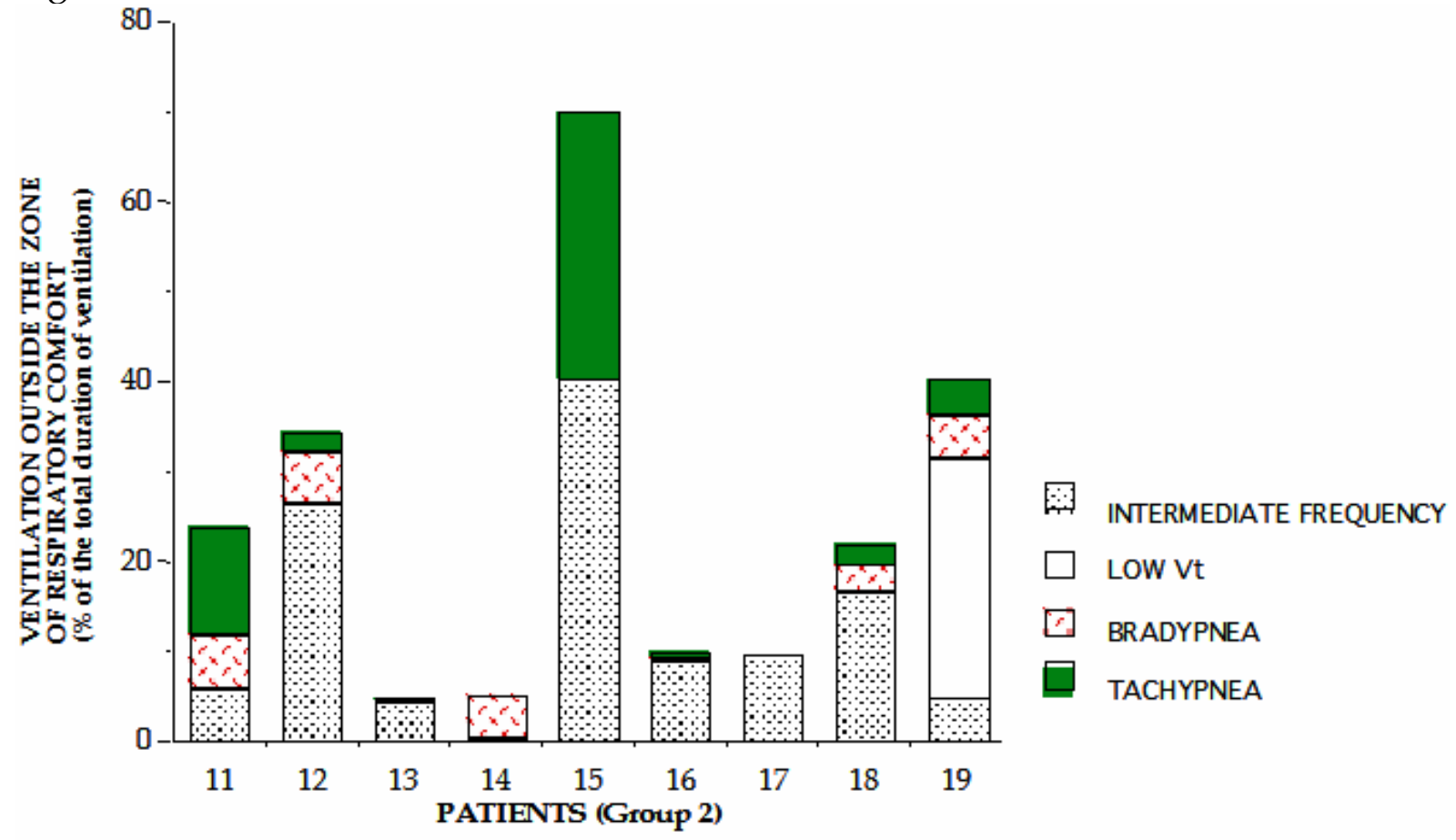

Duration of ventilation outside the zone of respiratory comfort for each patient with negative criteria for preweaning tests (group 2).

This figure shows the contributions to inadequate ventilation of intermediate frequency ( 28 breaths $/ \mathrm{min}<\mathrm{RR}<35$ breaths/min), bradypnea ( $R \mathrm{R}<12$ breaths $/ \mathrm{min}$ ), tachypnea $(\mathrm{RR} \geq 35$ breaths $/ \mathrm{min})$ and low $\mathrm{Vt}(<250 \mathrm{ml}$ and $<300 \mathrm{ml}$ for weights of $<55 \mathrm{Kg}$ and $\geq 55 \mathrm{Kg}$ respectively). However, one patient (\#15) was in a highly unstable condition $(70 \%$ of the time outside the comfort limits for the respiratory rate, with $40 \%$ spent in the intermediate zone).

The mean period spent outside the respiratory comfort limits constituted $28 \%$ of the total duration of ventilation (18\% in the intermediate zone). 
Table 1: Characteristics of the patient population.

Patients 1 to 10 constituted group 1 and had positive preweaning tests. Patients 11 to 19 constituted group 2 and were not weanable according to clinical evaluation. COLD $=$ Chronic Obstructive Lung Disease. SAPS = Simplified Acute Physiologic Score [11].

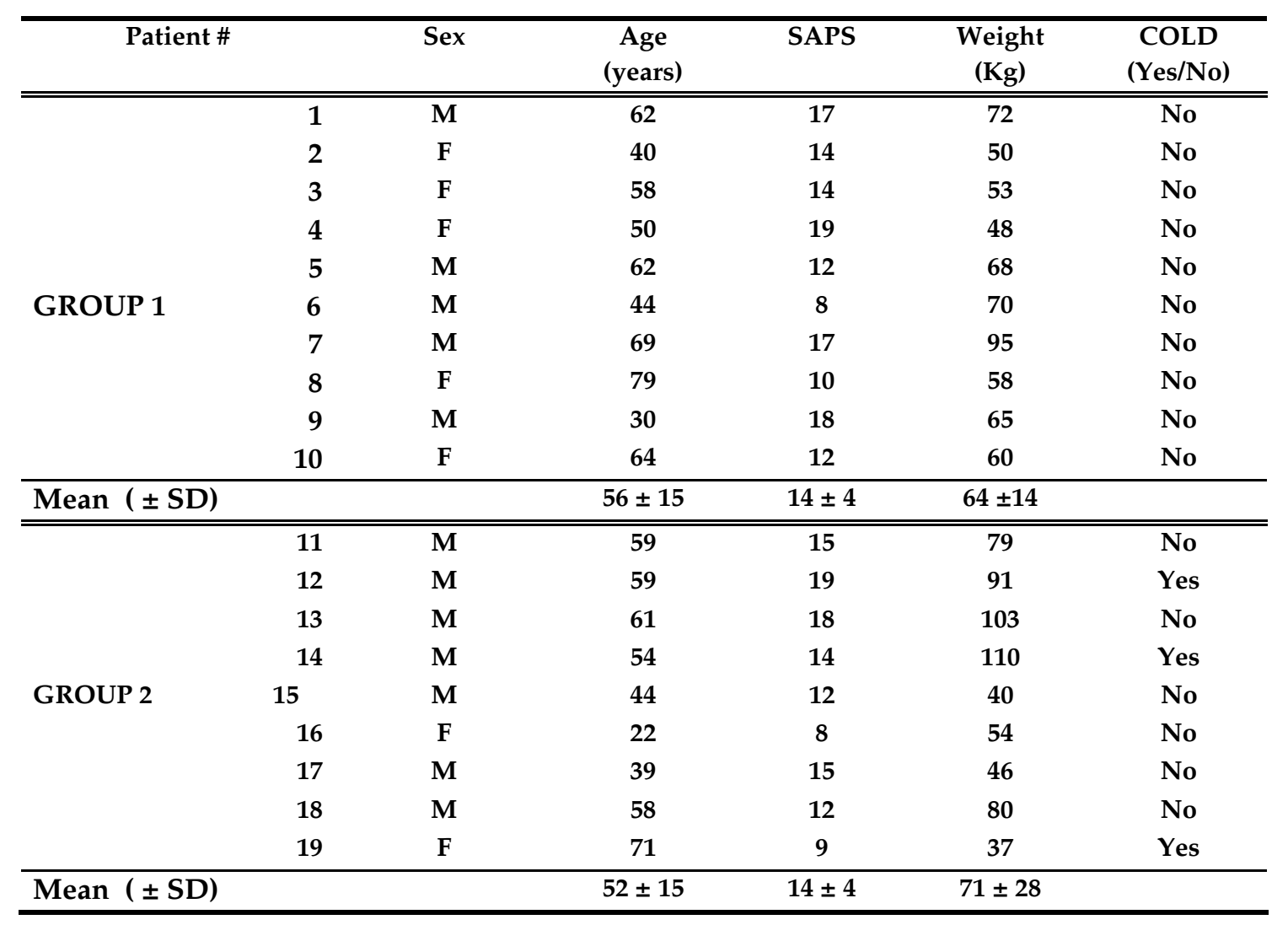


Table 2: Time spent by weanable patients (group 1) and non-weanable patients (group 2) in the zone of respiratory comfort versus the total ventilation period.

Data are (expressed as) means \pm standard deviation. Periods with adequate Vt, RR, and $\mathrm{PetCO}_{2}$ are expressed in percent of the duration of the ventilation with the system.

The zone of comfort was defined by : i) Vt > 250 and $300 \mathrm{ml}$ for patients weighting < $55 \mathrm{~kg}$ and > $55 \mathrm{~kg}$ respectively, ii) RR between 12 and 28 breaths/min iii) $\mathrm{PetCO}_{2}<$ $55 \mathrm{mmHg}$ and $<65 \mathrm{mmHg}$ for patients without and with COLD respectively.

For patients 9, 12,13 no PetCO 2 data were available.

\begin{tabular}{|c|c|c|c|c|c|c|c|}
\hline \multirow[t]{2}{*}{ Patient \# } & \multirow{2}{*}{\multicolumn{2}{|c|}{$\begin{array}{c}\text { Duration of } \\
\text { ventilation with the } \\
\text { system (min) }\end{array}$}} & \multicolumn{2}{|c|}{$\begin{array}{c}\text { Duration } \\
\text { of ventilation in the } \\
\text { zone of comfort }\end{array}$} & \multirow[t]{2}{*}{$\begin{array}{l}\text { Period with } \\
\text { satisfactory } \\
\text { Vt (\%) }\end{array}$} & \multirow[t]{2}{*}{$\begin{array}{l}\text { Period with } \\
\text { satisfactory } \\
\text { RR (\%) }\end{array}$} & \multirow[t]{2}{*}{$\begin{array}{l}\text { Period with } \\
\text { satisfactory } \\
\text { PetCO2 }(\%)\end{array}$} \\
\hline & & & $\min$ & $\%$ & & & \\
\hline \multirow{10}{*}{ GROUP 1} & 1 & 336 & 336 & 100 & 100 & 100 & 100 \\
\hline & 2 & 885 & 873 & 99 & 100 & 99 & 100 \\
\hline & 3 & 332 & 330 & 99 & 100 & 99 & 100 \\
\hline & 4 & 1628 & 1497 & 92 & 100 & 92 & 100 \\
\hline & 5 & 305 & 305 & 100 & 100 & 100 & 100 \\
\hline & 6 & 360 & 353 & 98 & 100 & 98 & 100 \\
\hline & 7 & 200 & 200 & 100 & 100 & 100 & 100 \\
\hline & 8 & 420 & 350 & 83 & 100 & 83 & 100 \\
\hline & 9 & 775 & 691 & 89 & 99 & 90 & - \\
\hline & 10 & 881 & 791 & 90 & 95 & 95 & 100 \\
\hline Mean ( \pm SD) & & $612 \pm 438$ & $573 \pm 378$ & $95 \pm 6$ & $99 \pm 2$ & $96 \pm 6$ & 100 \\
\hline \multirow{9}{*}{ GROUP 2} & 11 & 698 & 533 & 76 & 89 & 88 & 100 \\
\hline & 12 & 746 & 421 & 56 & 91 & 66 & - \\
\hline & 13 & 1282 & 1163 & 90 & 96 & 95 & - \\
\hline & 14 & 1258 & 841 & 67 & 72 & 95 & 100 \\
\hline & 15 & 965 & 289 & 30 & 100 & 29 & 100 \\
\hline & 16 & 423 & 381 & 90 & 100 & 90 & 100 \\
\hline & 17 & 1023 & 924 & 90 & 100 & 90 & 100 \\
\hline & 18 & 815 & 636 & 78 & 100 & 78 & 100 \\
\hline & 19 & 478 & 328 & 69 & 82 & 87 & 100 \\
\hline Mean ( \pm SD) & & $854 \pm 307$ & $523 \pm 331$ & $72 \pm 20$ & $92 \pm 10$ & $80 \pm 21$ & 100 \\
\hline
\end{tabular}

COLD $=$ Chronic Obstructive Lung Disease.

$\mathrm{Vt}=$ tidal Volume.

$\mathrm{RR}=$ Respiratory Rate.

PetCO 2 = end-tidal partial pressure of carbon dioxide. 
Table 3: Respiratory values for weanable patients (group 1) and non-weanable patients (group 2) during the ventilation periods spent inside and outside the zone of respiratory comfort.

This table shows the mean values of respiratory rate (RR) and tidal volume (Vt) while the patients were inside and outside of the zone of respiratory comfort (see definition in legend to table 2). Patients 1, 5 and 7 were in the zone of comfort throughout the study (see table 2). For patients 9, 12, 13 no $\mathrm{PetCO}_{2}$ data were available.

\begin{tabular}{|c|c|c|c|c|c|c|}
\hline Patient \# & & $\begin{array}{c}\text { RR } \\
\text { inside the zone } \\
\text { of comfort } \\
\text { (breaths/min) }\end{array}$ & $\begin{array}{c}\text { RR } \\
\text { outside the } \\
\text { zone } \\
\text { of comfort } \\
\text { (breaths/min) }\end{array}$ & $\begin{array}{l}\mathrm{Vt} \\
\text { inside the } \\
\text { zone } \\
\text { of comfort } \\
(\mathrm{ml})\end{array}$ & $\begin{array}{l}\text { Vt } \\
\text { outside the } \\
\text { zone } \\
\text { of comfort } \\
\text { (ml) }\end{array}$ & $\begin{array}{c}\text { PetCO2 } \\
\text { inside the zone } \\
\text { of comfort } \\
\text { (mmHg) }\end{array}$ \\
\hline \multirow{10}{*}{ GROUP 1} & 1 & 21 & - & 615 & - & 30 \\
\hline & 2 & 20 & 29 & 407 & 383 & 31 \\
\hline & 3 & 23 & 34 & 425 & 393 & 28 \\
\hline & 4 & 25 & 28 & 359 & 344 & 36 \\
\hline & 5 & 18 & - & 558 & $"$ & 33 \\
\hline & 6 & 23 & 29 & 658 & 669 & 29 \\
\hline & 7 & 19 & - & 617 & - & 33 \\
\hline & 8 & 21 & 27 & 527 & 512 & 27 \\
\hline & 9 & 23 & 29 & 444 & 376 & - \\
\hline & 10 & 19 & 18 & 410 & 397 & 34 \\
\hline Mean $\quad( \pm$ SD) & & $21 \pm 2$ & $28 \pm 5$ & $502 \pm 106$ & $439 \pm 114$ & $31 \pm 3$ \\
\hline \multirow{9}{*}{ GROUP2 } & 11 & 20 & 34 & 636 & 541 & 31 \\
\hline & 12 & 16 & 30 & 850 & 540 & - \\
\hline & 13 & 23 & 27 & 640 & 550 & - \\
\hline & 14 & 16 & 21 & 617 & 520 & 52 \\
\hline & 15 & 24 & 33 & 478 & 425 & 29 \\
\hline & 16 & 21 & 29 & 380 & 333 & 34 \\
\hline & 17 & 23 & 29 & 550 & 462 & 24 \\
\hline & 18 & 19 & 28 & 557 & 455 & 26 \\
\hline & 19 & 20 & 28 & 304 & 265 & 39 \\
\hline Mean $\quad( \pm$ SD) & & $20 \pm 3$ & $29 \pm 4$ & $557 \pm 160$ & $455 \pm 100$ & $34 \pm 10$ \\
\hline
\end{tabular}


